\title{
Exceptional diversity of Stefania (Anura, Cryptobatrachidae) II: Six species from Mount Wokomung, Guyana
}

\author{
Ross D. MacCulloch ${ }^{1}$, Amy Lathrop ${ }^{1}$ and Samir Z. Khan ${ }^{2}$ \\ ${ }^{1}$ Centre for Biodiversity and Conservation Biology, Royal Ontario Museum, 100 Queen's Park, Toronto, Ontario M5S \\ 2C6, Canada. E-mails: rossm@rom.on.ca, amyl@rom.on.ca. \\ ${ }^{2}$ Department of Biology, University of Guyana, Turkeyen Campus, Georgetown, Guyana.
}

\begin{abstract}
Exceptional diversity of Stefania (Anura, Cryptobatrachidae) II: Six species from Mount Wokomung, Guyana. Six species of Stefania were collected on Mount Wokomung, a tepui in the Pakaraima Mountains of Guyana. This unusually high diversity of Stefania is similar to that found on a neighbouring tepui, Mt. Ayanganna. The two tepuis support slightly different habitats. Conspecific Stefania from the two mountains differ somewhat in body size, toe disc size and colouration. Specimens from Mt. Wokomung are used to expand descriptions and distributions of some species.
\end{abstract}

Keywords: Anura, Cryptobatrachidae, Stefania, diversity, tepuis, Guyana.

\section{Introduction}

Since the genus Stefania was erected by Rivero ("1966” [1968]), 18 species have been described (Rivero “1966” [1968], 1970, Duellman and Hoogmoed 1984, Myers and Donnelly 1997, Señaris et al. “1996” [1997], MacCulloch and Lathrop 2002, Barrio-Amorós and Fuentes 2003). Recently Stefania has been removed from the Hylidae and placed into a new family, the Cryptobatrachidae (Frost et al. 2006). As in other Cryptobatrachids, the eggs of Stefania are carried on the female's back, and hatch into froglets, without a tadpole stage (Duellman and Hoogmoed 1984, Jungfer and Boehme 1991).

Received 2 September 2005.

Accepted 3 April 2006.

Distributed September 2006.
Stefania is a Guiana Shield endemic, occurring from the Essequibo River in Guyana to western Amazonas State, Venezuela, and in northern Brazil (MacCulloch and Lathrop 2002, Barrio-Amorós and Fuentes 2003, Caramaschi and Niemeyer 2005). Many species occur at high elevations on tepuis in the Guiana Shield region. Most accounts of Stefania report only one or two species per mountain, with the exception of Mount Ayanganna, Guyana, where five species were collected sympatrically on the slopes at 1490-1550 m, plus two other species at the base, at $870 \mathrm{~m}$ (MacCulloch and Lathrop 2002).

Mount Wokomung (0504'53” N, 5950'28” $\mathrm{W})$, south of Mt. Ayanganna, is one of the easternmost tepuis in the Guiana Shield (Figure 1). It is separated from Ayanganna by $37 \mathrm{~km}$ of uplands, which support lower montane forest 
habitat (Huber et al. 1995). Herein we report on Stefania from Mount Wokomung. Comparison of the faunas of these neighbouring mountains provides insight into the zoogeography of the Guiana region.

In October-November 2004, collections were made at four locations on Mount Wokomung: the base of the mountain in lower montane forest, $698 \mathrm{~m}$; two locations on the north face in montane or upper montane forest, 1234 and $1411 \mathrm{~m}$; and on the summit in tepui bog habitat, $1698 \mathrm{~m}$. Additional collections were made en route to the mountain in lower montane forest, $600-700 \mathrm{~m}$.

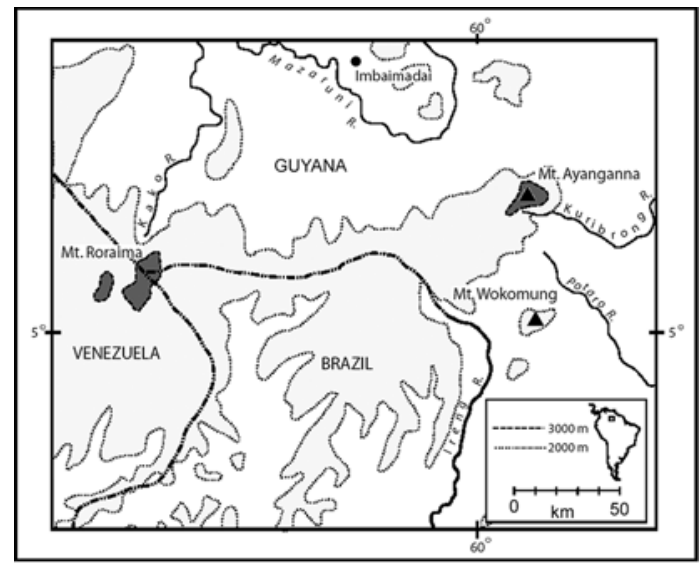

Figure 1 - Map of western Guyana showing the locations of Mount Wokomung and Mount Ayanganna.
The higher-elevation habitat on Wokomung is different from that on Ayanganna. The northeastern slope of Ayanganna, where the specimens reported in MacCulloch and Lathrop (2002) were collected, consists of a series of relatively flat plateaus separated by steep slopes. Above $1200 \mathrm{~m}$ the plateaus support low-canopy high-tepui forest with dense ground cover, whereas the slopes are covered by mediumcanopy montane forest. Most collections from Ayanganna were made on the plateaus. In contrast, Wokomung has only a few small plateaus, and its slopes at comparable elevations are covered in medium-canopy montane forest, with a more open understory than is found on Ayanganna (Figure 2A; contrast with Figure 1 in MacCulloch and Lathrop 2002). The summit of Wokomung is a shallow bowl, with tepui bog habitat at its centre and montane forest at the edge of the summit (Figure 2B).

\section{Material and Methods}

Specimens were collected by hand, usually at night. Most Stefania were on vegetation, with few on the ground. Specimens were euthanized using clove oil diluted in 95\% ethanol, then fixed in formalin; tissue (liver) was removed and preserved in 95\% ethanol. Collected specimens were compared with museum specimens (Appendix I) or published descriptions. New collections of Stefania were used to redefine

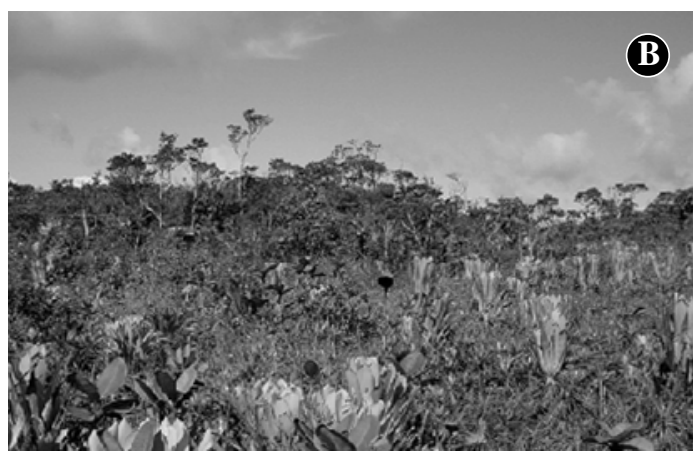

Figure 2 - Habitat of Stefania on Mount Wokomung. (A) Montane forest on the north slope, 1411 m; (B) Evergreen tepui bog habitat at the summit, $1698 \mathrm{~m}$. 
distributions and elaborate upon existing species descriptions. All measurements were made with digital calipers and rounded to $0.1 \mathrm{~mm}$. Interdigital webbing is described using the formula of Lescure (1975) and Myers and Duellman (1982), as refined by Savage and Heyer (1997). All specimens described herein are in the collections of the Centre for the Study of Biological Diversity at the University of Guyana (CSBD) or the Royal Ontario Museum (ROM).

\section{Results}

Six species of Stefania (S. ackawaio, S. ayangannae, S. coxi, S. evansi, S. roraimae and $S$. woodleyi) were collected from various habitats on Mount Wokomung. Each species is treated separately, below.

Stefania ackawaio MacCulloch and Lathrop Stefania ackawaio MacCulloch and Lathrop [Holotype ROM 39473,

from Mt. Ayanganna, Guyana] 2002: 334.

At Ayanganna only one adult male of $46 \mathrm{~mm}$ SVL, two subadult females and one juvenile were collected at 1490-1550 m. At Wokomung this species was abundant at both $1234 \mathrm{~m}$ and $1411 \mathrm{~m}$ and the number of specimens collected was greater: 14 females ranging from 39-66 mm SVL, nine males, 34-48 mm SVL and six independent juveniles, 20-22 mm SVL. Additional individuals were seen but not captured.

In general, specimens from Wokomung resemble the type series from Mount Ayanganna, although some individuals at Wokomung have a grey background colour, rather than the brown background which is present in animals from Ayanganna. Some individuals from Wokomung have patches of reddish colour on dorsum and limbs, which are also found in sympatric $S$. ayangannae and $S$. evansi (Figure 3A). The number of vomerine teeth is 6-9.

Inclusion of the specimens from Wokomung expands the webbing formula of S. ackawaio to
I $\left(2-2^{1 / 2}\right)-\left(2-2^{1 / 2}\right)$ II $\left(1 \frac{13 / 4-2)}{-}\left(2^{1 / 2-2}\right)\right.$ III $\left(2^{1 / 4}-\right.$ $21 / 2)-(3-31 / 4)$ IV $\left(3-3 \frac{1 / 4}{4}\right)-\left(2-2^{1 / 4}\right) \mathbf{V}$.

Stefania ackawaio from Wokomung exhibited variation in size of finger discs, although this variation is less marked than in some other species of Stefania (see below). In larger specimens, finger and toe discs are proportionally larger than in smaller individuals. The largest finger disc, on the largest specimen, covers $75 \%$ of the tympanum, while in individuals with smaller discs about $66 \%$ of the tympanum is covered.

No females were carrying eggs or juveniles, and none had enlarged ova. However, two females retained remnants of the dorsal mucoid layer, indicating that they had recently carried juveniles.

Stefania ackawaio was much more abundant at Wokomung than at Ayanganna, where few were collected at 1490-1550 m. The reason for this is unknown, although it may be that $S$. ackawaio prefers the more open higher-canopy habitat found on Wokomung rather than the dense low-canopy habitat on Ayanganna.

Stefania ayangannae MacCulloch and Lathrop Stefania ayangannae MacCulloch and Lathrop [Holotype ROM 39501,

from Mt. Ayanganna, Guyana] 2002: 329.

Stefania ayangannae was the most abundant anuran species encountered at $1411 \mathrm{~m}$, and was fairly numerous at $1234 \mathrm{~m}$. At both locations $S$. ayangannae were found primarily on leaves or branches. On the summit of Wokomung (1698 $\mathrm{m})$, in tepui bog habitat, five adult females were found concealed in the centre of large terrestrial bromeliads. At the rim of the summit, in lowcanopy forest habitat, a subadult of $29 \mathrm{~mm} \mathrm{SVL}$ was collected. In all 15 females of $32-50 \mathrm{~mm}$ SVL, six males, 32-40 mm SVL and five juveniles or subadults, $16-30 \mathrm{~mm}$ SVL were collected. Additional individuals were seen but not captured.

Stefania ayangannae from Wokomung are similar to those from Ayanganna except that the 

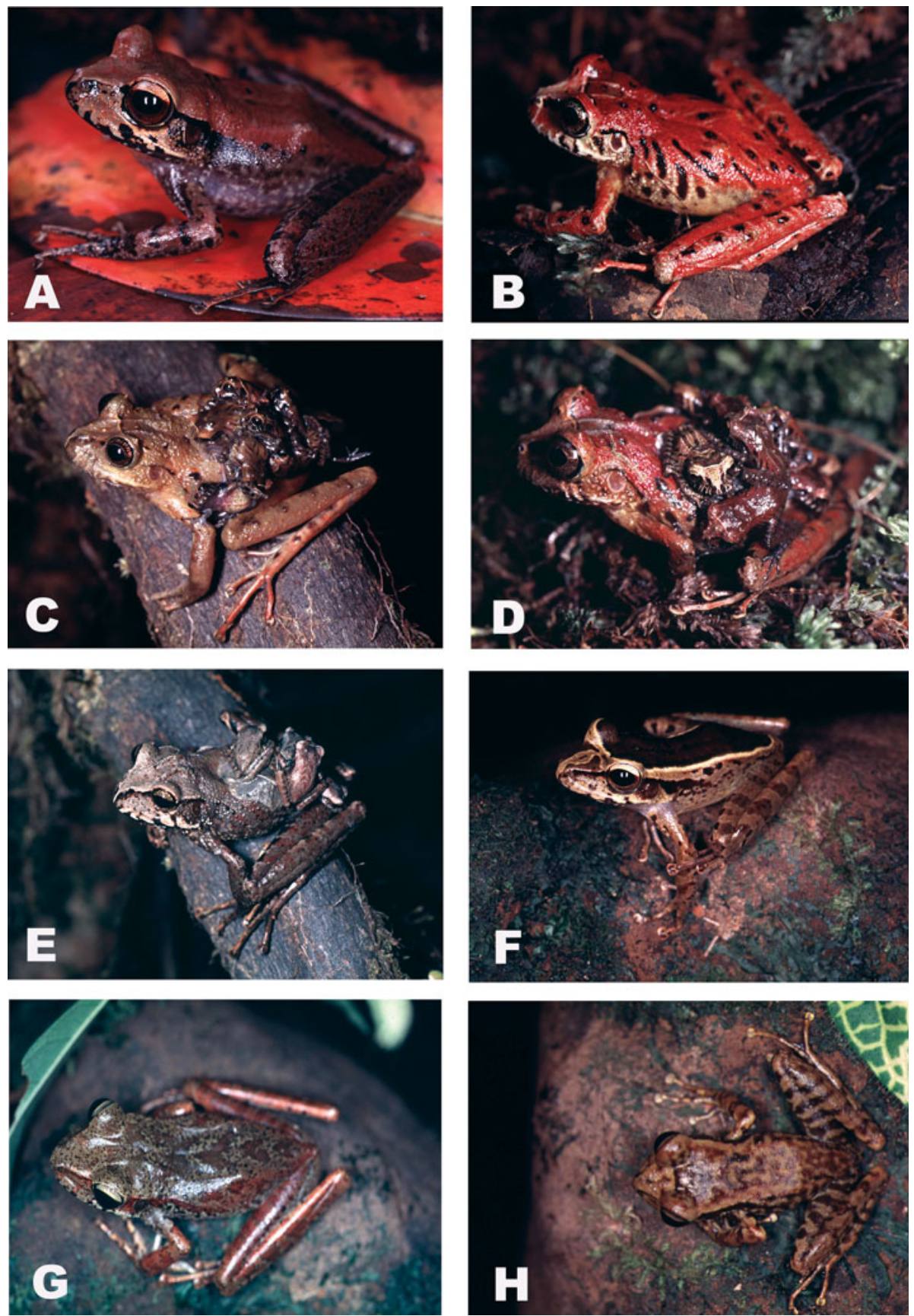

Figure 3 - Stefania from Mount Wokomung. (A) Stefania ackawaio, ROM 42807, female, $57 \mathrm{~mm}$ SVL; (B) Stefania ayangannae ROM 42907, female, $42 \mathrm{~mm}$ SVL; (C) Stefania ayangannae ROM 42952, $50 \mathrm{~mm}$ SVL; (D) Stefania ayangannae, ROM 42918, $50 \mathrm{~mm}$ SVL; (E) Stefania coxi, ROM 42856, female, $62 \mathrm{~mm}$ SVL; (F) Stefania evansi, striped morph, ROM 42891, female, $50 \mathrm{~mm}$ SVL; (G) Stefania evansi, brown morph with chevron pattern, ROM 42879, female, 72 mm SVL; (H) Stefania woodleyi, ROM 42832, male, 41 mm SVL. 
second finger is slightly shorter in specimens from Wokomung, reaching the ultimate joint on the first finger (reaches base of disc in frogs from Ayanganna). Maximum size at Wokomung (51 $\mathrm{mm}$ for females, $40 \mathrm{~mm}$ for males) exceeded that recorded from Ayanganna (48 and $37 \mathrm{~mm}$ ). Many specimens from Wokomung, of all sizes, had reddish dorsal background colour rather than the yellow background which predominated at Ayanganna (Figure 3B - contrast with Figure 3 in MacCulloch and Lathrop 2002); reddish colour occurred in S. ackawaio and S. evansi from Wokomung as well.

In general, larger individuals of $S$. ayangannae of both sexes have a more tubercular dorsum and darker colouration than do smaller individuals (Figure 3C). In some larger individuals the upper rim of the palpebrum carries a dark brown band, rather than the yellow band present in most specimens from Wokomung and all individuals from Ayanganna. Vomerine teeth 5 .

The webbing formula for S. ayangannae, based on specimens from Wokomung and Ayanganna, is I $\left(2 \frac{1 / 2-3}{2}\right)-\left(2^{1 / 2}-3\right)$ II $\left(2-2^{+}\right)-\left(3-3^{1 / 4}\right)$ III $\left(2^{1 / 4-21 / 2}\right)-\left(3^{1 / 2-3}-3^{3 / 4}\right)$ IV $\left(3^{1 / 2-33 / 4}\right)-\left(2-2^{1 / 4}\right)$ V. Although there is a slight tendency for larger individuals to have more extensive webbing, this correlation is not as marked as it is in S. evansi. Stefania ayangannae has the least toe webbing of any Stefania (MacCulloch and Lathrop 2002).

Stefania ayangannae also exhibits variation in size of finger discs (Figure 4). In most individuals from Wokomung the largest finger disc is $75 \%$ of the tympanum diameter, as reported in MacCulloch and Lathrop (2002), while in others it is equal to or greater than the tympanum diameter. About one-third of $S$. ayangannae from Wokomung have large discs; increase in disc size is not related to sex, but it is more common in larger individuals. Re-examination of the specimens from Ayanganna found that the phenomenon of large discs is less common there, with larger discs present in only two large females and one subadult.

The five females collected on the summit of Wokomung are all large, 47-50 mm SVL. All were carrying juveniles, either five $(\mathrm{N}=2)$ or eight $(\mathrm{N}=3)$ juveniles (Figure $3 \mathrm{D})$. Two other females, 48 and $50 \mathrm{~mm} \mathrm{SVL}$, collected in forest habitat at $1411 \mathrm{~m}$, were carrying four and six juveniles respectively. The largest number of offspring reported in S. ayangannae at Ayanganna was four (MacCulloch and Lathrop 2002).

Intra- and interpopulation variation in disc size, finger length, skin texture and colouration occurs in Stefania ayangannae from Wokomung and Ayanganna. This variation may be indicative of the presence of cryptic species. However, until a more detailed study can be undertaken, we provisionally assign the specimens from both locations to the same species.

Stefania coxi MacCulloch and Lathrop Stefania coxi MacCulloch and Lathrop [Holotype ROM 39477,

from Mt. Ayanganna, Guyana] 2002: 336.

One female of $62 \mathrm{~mm} \mathrm{SVL}$, carrying 4 juveniles, was collected on the summit of Mt. Wokomung in tepui bog habitat, on a dense mat of bromeliads (Figure 3E).

The adult resembles the specimens from Ayanganna with the following differences: head less broad, although still wider than long (width 1.1 X length); supratympanic crests slightly less prominent; largest finger disc slightly smaller than tympanum diameter; supernumerary palmar and plantar tubercles less prominent; colour grey, rather than brown. Vomerine teeth 5 . These differences are within the range of interpopulation variation.

The foot webbing formula for all individuals from both locations is I $\left(2^{+}-2 \frac{1}{4}\right)-2 \frac{1}{4} \mathbf{~ I I ~}\left(2-2^{+}\right)-$ $\left(3-3^{+}\right)$III $\left(2-2^{+}\right)-\left(3 \frac{1}{2}-3 \frac{1}{4}\right)$ IV $3 \frac{1}{2}-\left(2-2^{+}\right)$V.

The four juveniles measured 18-19 mm SVL, and none retained any visible vestige of yolk, so it is assumed that they are near to attaining independence. The mucoid layer on the female's back retained the impression of 7-8 eggs, indicating that other juveniles had recently left the female's care. This species is the only 
representative of the broad-headed $S$. goini group that is known from Guyana. Members of this group seem to prefer tepui summit habitat (Señaris et al. "1996” [1997]). Stefania coxi was found only on the summit of Wokomung, despite intensive collecting on the slopes. On Ayanganna it was found in low-canopy forest (MacCulloch and Lathrop 2002). This indicates that $S$. coxi prefers low-canopy or summit habitat rather than medium- or high-canopy forest.

\section{Stefania evansi Rivero}

Hyla evansi Boulenger [Holotype BMNH 1947.106 from Groete Creek, Guyana] 1904: 106.

Stefania evansi Rivero “1966” [1968]: 143.

This species was abundant in suitable habitat at lower elevations, at two locations near the base of Mount Wokomung between 680-698 m. None were encountered at the next highest site (1234 m). All specimens were found on vegetation near streams in the forest. Two colour morphs, uniform brown and dorsolaterally striped (morphs A and B of Duellman and Hoogmoed 1984) were collected, the former at both low-elevation locations, the latter at one location only, $698 \mathrm{~m}$ elevation. Of the 32 specimens collected, 26 were uniform and six were striped (Figure 3F).

Females measured 45-78 mm SVL ( $\mathrm{N}=9)$, males 46-52 mm ( $\mathrm{N}=6)$, subadults $29-40 \mathrm{~mm}$ $(\mathrm{N}=13)$. The largest striped individuals, two females, measured $50 \mathrm{~mm}$ SVL. One adult female of $72 \mathrm{~mm}$ SVL (Figure 3G) retained an indistinct dorsal chevron pattern, which is typically present in juveniles (Duellman and Hoogmoed 1984, MacCulloch and Lathrop 2002). Four independent juveniles measuring 19.5-22 mm SVL were collected; three have the dorsal chevron pattern while one was unmarked. Vomerine teeth 7-10.

The foot webbing formula of individuals from several locations in the Pakaraima region is I $1-\left(1^{+}-1 \frac{1 / 4}{4}\right)$ II $1-\left(1^{+}-1 \frac{1}{2}\right)$ III $\left(1-1^{+}\right)-(2-$ $\left.2 \frac{1}{4}\right)$ IV $\left(2-2 \frac{1}{4}\right)-\left(1-1^{+}\right)$V. Foot webbing is slightly more extensive on larger specimens than on smaller individuals. Stefania evansi has the most extensive webbing of the genus.

Most adults, regardless of colour pattern, had red canthal and supratympanic lines. Some individuals of uniform brown colour pattern had reddish patches or spots on dorsum, flanks and limbs (Figure 3G). The red colour fades in preservative. Venter white, with or without brown mottling. Dark brown or black crossbands on thighs present or absent, but all individuals have black spots on the distal portion of the anterior surface of the thigh.

Specimens of $S$. evansi with dorsolateral stripes (Pattern B of Duellman and Hoogmoed 1984 ) bear a superficial resemblance to $S$. roraimae. In addition to the obvious differences in toe webbing and elevational preference, they can be readily distinguished by canthal profile, skin texture and colouration of thigh, flank and venter (MacCulloch and Lathrop 2002).

Some individuals have unusually large finger discs. It has been stated that the finger and toe discs in $S$. evansi are approximately equal in size (Señaris et al. “1996” [1997], Duellman and Hoogmoed 1984). This is true for most individuals, but in some specimens, the finger discs are unusually large (Figure 5). Most specimens with proportionally larger discs are larger individuals, although not all large $S$. evansi had larger discs, and larger discs were present in some smaller animals of both sexes as well. This situation seems the same as in S. ayangannae.

No enlarged ova or other internal evidence of impending reproductive activity were seen. Dry season was ending, and the NovemberDecember rainy season imminent. However, the collection of several small juveniles, apparently newly independent, indicated that the reproductive season was nearing completion. At Ayanganna one female $S$. evansi with juveniles was collected at the same time of year.

Many characteristics traditionally used to identify this species are variable. The name Stefania evansi has been applied to all Stefania 


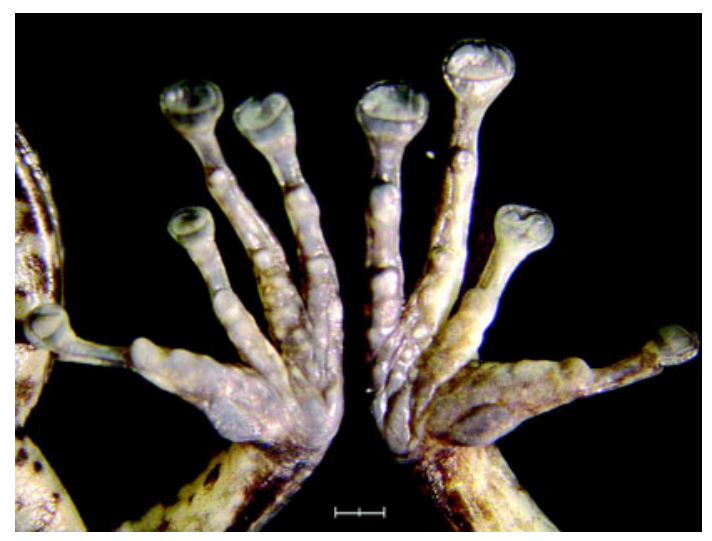

Figure 4 - Variation in size of finger discs in similarsized Stefania ayangannae from Mount Wokomung. Left, ROM 42913 (49 mm SVL); right, ROM 42946 (50 mm SVL). Scale bar $=2 \mathrm{~mm}$.

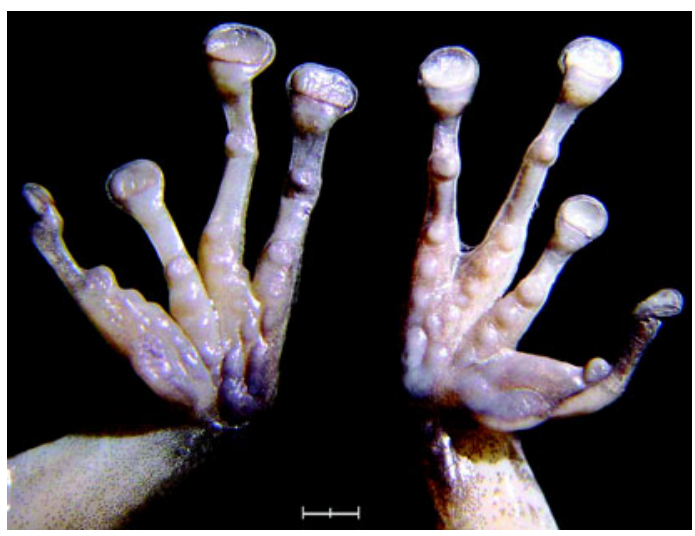

Figure 5 - Variation in size of finger discs in similarsized Stefania evansi from Mount Wokomung. Left, ROM 42891 (49 mm SVL); right, ROM 42875 (49 mm SVL). Scale bar $=2 \mathrm{~mm}$.

disc covered $33 \%$ of the tympanum diameter, while in the adults from Ayanganna the disc covered $75 \%$ of the tympanum diameter (Duellman and Hoogmoed 1984, MacCulloch and Lathrop 2002). In the more extensive sample from Wokomung this ratio varies from about $50 \%$ to about $75 \%$, with no difference between sexes. Although smaller individuals ( $<40 \mathrm{~mm}$ SVL) tend to have relatively smaller discs than larger animals, variation in disc size is not completely correlated with SVL. Variation in disc size in S. roraimae between Ayanganna and Wokomung is not as marked as it is in $S$. ayangannae.

Foot webbing formula for individuals from Ayanganna, Wokomung and Roraima is I (2-2) - (2-21/2) II (13/4-2) - (21/2-3) III (2-21/2) - (3-33/4) IV $\left(3-3^{1 / 2}\right)-\left(2-2^{1 / 2}\right) \mathbf{V}$. Vomerine teeth 8-10.

In general the specimens from Wokomung have darker mottling ventrally than do specimens from Ayanganna. Some specimens from Wokomung have small dark spots in the creamcoloured dorsolateral and interorbital lines; these spots are not present in specimens from Ayanganna. In the specimens from Wokomung the dark colours are predominantly grey, whereas the specimens from Ayanganna are 
brown. Juvenile S. roraimae are uniformly yellow-green at night, with only the outline of the stripes visible. By day they resemble adults, with dark ground colour and light stripes.

\section{Stefania woodleyi Rivero \\ Stefania woodleyi Rivero [Holotype BMNH \\ 1967.654 from Mount Kanaima, Guyana] 1968: 147.}

Two adult males of 40 and $41 \mathrm{~mm}$ SVL and two juveniles of $19 \mathrm{~mm}$ SVL were collected at the base of Wokomung, at $698 \mathrm{~m}$ (Figure 3H). The latter were identified as $S$. woodleyi because their reduced toe webbing and dorsal colouration conform to the unique mottled pattern of this species. The only other species of Stefania collected at this location was S. evansi, which has more extensive toe webbing.

Following examination of $S$. woodleyi from several locations, the toe webbing formula can be expanded to $\mathbf{I}\left(2^{+}-2^{1 / 4}\right)-2^{1 / 2} \mathbf{I I}\left(2^{-}-2\right)-\left(3-3^{+}\right)$ III $\left(2^{\left.1 / \frac{1}{4}-2 \frac{1}{2}\right)}-\left(3^{1 / 2-2}-3^{3 / 4}\right)\right.$ IV $3 \frac{1}{2}-\left(2^{+}-2^{1 / 2}\right)$ V. Vomerine teeth 5 . The largest finger disc covers about $66 \%$ of the tympanum diameter.

Mount Wokomung is within the range of $S$. woodleyi, which has been collected from several locations in the southern Pakaraima region (MacCulloch and Lathrop 2002).

\section{Discussion}

\section{Morphology}

Toe disc size variation was found in four species of the $S$. evansi group at Mt. Wokomung - S. ackawaio, S. ayangannae, S. evansi and S. roraimae. Examination of specimens from Mt. Ayanganna shows that disc size variation occurs in some $S$. ayangannae from that location. Variation was not apparent in S. ackawaio, $S$. evansi or S. roraimae from Mt. Ayanganna, but sampling of these species at Ayanganna was low in comparison with Mt. Wokomung. In the single specimen of $S$. roraimae from Mt. Rorai$\mathrm{ma}$, the finger discs are notably smaller than in the specimens from Wokomung or Ayanganna (Duellman and Hoogmoed 1984, MacCulloch and Lathrop 2002). Although larger discs occur more frequently in larger animals, the relationship between body size and disc size is not clear. This phenomenon merits further study.

Many Stefania from Mt. Wokomung exhibited a reddish colouration not seen in specimens from other locations (Figure 3A, B, $D, G)$. This colour was also seen in some other amphibian taxa (unpublished data). There were many plants with red leaves on Wokomung, and red colour may confer a selective advantage in amphibian camouflage.

MacCulloch and Lathrop (2002) pointed out that juvenile Stefania can be difficult to identify because many of the characters used for identification, such as skin texture, webbing and frontoparietal ridges, are not well-developed in juveniles. Juvenile colour pattern is also an unreliable identification tool; conspecific juveniles and even juveniles from the same brood may have different colour patterns (Figure 3D).

\section{Reproduction}

It is difficult to reach any conclusions about reproduction in Stefania at Mt. Wokomung. All females encountered on the summit of Wokomung, five $S$. ayangannae and one $S$. coxi, were carrying juveniles. Of the 10 female $S$. ayangannae collected on the slopes, two from 1411 $\mathrm{m}$ were carrying juveniles. Females of $S$. ayangannae that carried juveniles measured 47-50 mm SVL; numbers of juveniles carried were 4 , 5 , 6 , or 8 , with no correlation between size of female and number of offspring. Juveniles measured 14-16 mm SVL.

Two of 14 female $S$. ackawaio collected retained some remnant of the dorsal mucoid layer. No female $S$. evansi or $S$. roraimae had any indication of reproductive activity, although newly independent juveniles of both species were collected. Similarly, two juvenile $S$. woodleyi were collected, although no adult females of this species were encountered. 
It appears that Stefania species, even those that occur syntopically, do not reproduce at exactly the same time. The humid environment on tepuis and the absence of an aquatic larval stage may render these frogs relatively independent of seasonal reproductive patterns.

Reproduction in Stefania at the summit does not seem to be synchronous with that of Stefania on the slopes. This may be because the bromeliad microhabitat provides water and shelter from the summit winds, and it may provide $S$. ayangannae with suitable reproductive habitat throughout the year.

\section{Habitat}

Specimens collected at 1234-1411 m on Wokomung were in medium montane forest habitat, whereas the $1490-1550 \mathrm{~m}$ sites on Ayanganna supported wet low evergreen hightepui forest (Huber et al. 1995). Stefania ackawaio and S. roraimae were more abundant on Wokomung than on Ayanganna; habitat may be a contributing factor to this difference. However, Stefania ayangannae was abundant on both mountains. It was most commonly collected in both high- and low-canopy forest, from 1234-1698 m elevation, but it was also collected in summit bog habitat on Wokomung, at $1698 \mathrm{~m}$. Perhaps S. ayangannae can be viewed as an opportunistic colonizer, a common slope species which has been able to survive the harsh summit habitat by using the microhabitat within bromeliads.

Stefania coxi, collected in high-tepui forest at Ayanganna, was found only in tepui bog habitat on the summit of Wokomung, at $1698 \mathrm{~m}$, despite intensive collecting effort at lower elevations. This species may not occur in medium montane forests; it is a member of the $S$. goini group, whose members seem to prefer high-tepui habitat rather than the taller-canopy habitat often found on tepui slopes (Señaris et al. "1996" [1997]). Stefania coxi and S. ayangannae were the only amphibians collected in tepui bog habitat at the summit, although several individuals of an unknown species of Colostethus were heard calling there.

Stefania evansi and S. woodleyi were collected in submontane forest at Wokomung, at about $700 \mathrm{~m}$. This habitat is similar to that in which these species have been collected elsewhere (MacCulloch and Lathrop 2002).

\section{Zoogeography}

The specimens of Stefania ackawaio, S. ayangannae and $S$. coxi from Mount Wokomung extend the range of these species, previously known only from their type locality on Mount Ayanganna, $37 \mathrm{~km}$ north of Wokomung. These three species were collected at $1490-1550 \mathrm{~m}$ on Ayanganna, in low-canopy high-tepui forest. At Wokomung S. ackawaio and S. ayangannae were abundant at both 1234 and $1411 \mathrm{~m}$, in medium montane forest. At the summit of Wokomung, in tepui bog habitat, S. ayangannae and $S$. coxi were collected.

Stefania roraimae was known from both Ayanganna and Roraima, where it was collected at $1400-1550 \mathrm{~m}$. At Wokomung it was abundant at 1234 and $1411 \mathrm{~m}$.

Stefania evansi and S. woodleyi have been recorded from other nearby locations (MacCulloch and Lathrop 2002); both species occur in lowland, submontane or lower montane forest in western Guyana, below $900 \mathrm{~m}$.

There was no overlap between the high- and low-elevation species of Stefania at Wokomung. Stefania ackawaio, S. ayangannae, S. coxi and $S$. roraimae were collected only at or above $1234 \mathrm{~m}$, while S. evansi and S. woodleyi were collected only at 600-700 m. The lower elevation limits of the former species, and the upper limits of the latter, are not known. Nor is it known whether there is a point at which the high- and low-elevation species are sympatric.

The unprecedented diversity of Stefania at Mount Ayanganna led MacCulloch and Lathrop (2002) to speculate that it might be a centre of dispersal for the genus. The discovery of six species on Mount Wokomung shows that the 
phenomenon of high diversity in Stefania is not limited to a single location. It is anticipated that further investigations in the Guiana highlands will yield other incidences of high diversity in Stefania.

\section{Acknowledgements}

Specimens were collected under Permit Number 121004BR019 and exported under Permit Number 191104SP016 issued by the Guyana Environmental Protection Agency. All specimens were collected according to approved animal use protocols. The field assistance of B. Hubley, R. James, C. Alban, M. Alban, R. Benjamin, N. Ignatius and M. Williams was greatly appreciated. We also thank I. Ramdass, J. Lidell, C. Kelloff, A. Bernard-Barry, C. Bernard and K. Erskine. This study was made possible with the generous support of the ROM Reproductions Acquisitions Fund and the ROM Department of Natural History to R.D. MacCulloch. This is contribution 329 of the Centre for Biodiversity and Conservation Biology, ROM and number 106 in the Smithsonian's Biological Diversity of the Guiana Shield Program publication series.

\section{References}

Barrio-Amorós, C. L. and O. Fuentes. 2003. A new species of Stefania (Anura: Hylidae: Hemiphractinae) from the summit of Cerro Autana, estado Amazonas, Venezuela. Herpetologica 59: 506-514.

Boulenger, G. A. 1904. Description of a new Tree-Frog of the Genus Hyla, from British Guiana, carrying eggs on the back. Proceedings of the Zoological Society of London 1904 II(I): 106.

Caramaschi, U. and H. Niemeyer. 2005. Geographic distribution: Stefania tamacuarina. Herpetological Review 36: 77.

Duellman, W. E. and M. S. Hoogmoed. 1984. The taxonomy and phylogenetic relationships of the hylid frog genus Stefania. University of Kansas Museum of $\mathrm{Na}$ tural History Miscellaneous Publications 75: 1-39.

Frost, D. R., T. Grant, J. Faivovich, R. H. Bain, A. Haas, C. F. B. Haddad, R. O. de Sá, A. Channing, M.
Wilkinson, S. C. Donnellan, C. J. Raxworthy, J. A. Campbell, B. L. Blotto, P. Moler, R. C. Drewes, R. A. Nussbaum, J. D. Lynch, D. M. Green and W. C. Wheeler. 2006. The amphibian tree of life. Bulletin of the American Museum of Natural History 297: 1-370.

Hoogmoed, M. S. 1979. The herpetofauna of the Guiana region. Pp. 241-279 in W. E. Duellman (ed.), The South American herpetofauna: its origin, evolution and dispersal. Monographs of the University of Kansas Museum of Natural History 7: 1-485.

Huber, O., G. Gharbarran and V. Funk. 1995. Vegetation map of Guyana. Centre for the Study of Biological Diversity, University of Guyana, Georgetown, Guyana.

Jungfer, K-H. and W. Boehme. 1991. The backpack strategy of parental care in frogs, with notes on frogletcarrying in Stefania evansi (Boulenger, 1904) (Anura: Hylidae: Hemiphractinae). Revue française d'Aquariologie 18: 91-96.

Lescure, J. 1975. Contribution à l'étude des amphibiens de Guyane française. III. Une nouvelle espèce de Colostethus (Dendrobatidae): Colostethus degranvillei nov. sp. Bulletin du Muséum National d'Histoire Naturelle 3(293), Zool. 203: 413-420.

MacCulloch, R. D. and A. Lathrop. 2002. Exceptional diversity of Stefania (Anura: Hylidae) on Mount Ayanganna, Guyana: three new species and new distribution records. Herpetologica 58: 327-346.

Myers, C. W. and M. A. Donnelly. 1997. A tepui herpetofauna on a granitic mountain (Tamacuari) in the borderland between Venezuela and Brazil: report from the Phipps Tapirapeco expedition. American Museum Novitates 3213: 1-71.

Myers, C. W. and W. E. Duellman. 1982. A new species of Hyla from Cerro Colorado, and other tree frog records and geographical notes from western Panama. American Museum Novitates 2752: 1-32.

Rivero, J. “1966” [1968]. Notes on the genus Cryptobatrachus (Amphibia, Salientia) with the description of a new race and four new species of a new genus of hylid frogs. Caribbean Journal of Science 6: 137-149.

Rivero, J. 1970. On the origin, endemism, and distribution of the genus Stefania Rivero (Amphibia, Salientia) with the description of a new species from southeastern Venezuela. Boletin de la Sociedad Venezolana de Ciencias Naturales 28: 456-481.

Savage, J. M. and W. R. Heyer. 1997. Digital webbing formulae for amphibians: a refinement. Herpetological Review 28: 131.

Señaris, J. C., J. Ayarzagüena and S. Gorzula. “1996” [1997]. Revisión taxonómica del género Stefania (Anura: Hylidae) en Venezuela con la descripción de cinco nuevas especies. Publicaciones de la Asociación de Amigos de Doñana 7: 1-57. 
Appendix I - Specimens Examined

Stefania ackawaio - GUYANA: District 8: Mount Wokomung (ROM 42804-42831, CSBD Field \# 15441-2, 15454, 15456); District 7: Mount Ayanganna (ROM 3947339476).

Stefania ayangannae - GUYANA: District 8: Mount Wokomung (ROM 42893-42952, CSBD Field \# 15494); District 7: Mount Ayanganna (ROM 39501-39551).

Stefania coxi - GUYANA: District 8: Mount Wokomung (ROM 42856-42860); District 7: Mount Ayanganna (ROM 3947739480).
Stefania evansi - GUYANA: District 8: Mount Wokomung (ROM 42861-42892); Tukeit (ROM 20555, 20559); District 7: Mount Ayanganna (ROM 39450-39463).

Stefania roraimae - GUYANA: District 8: Mount Wokomung (ROM 42836-42855, CSBD Field \# 15438-40, 15445, 15452); District 7: Mount Ayanganna (ROM 39466-39469).

Stefania woodleyi - GUYANA: District 8: Mount Wokomung (ROM 42832-42835); Tukeit (ROM 20570); Paramakatoi (ROM 2842528426); District 7: Mount Ayanganna (ROM 39465). 